\title{
Preliminary Evaluations of the Antibacterial Activity of Tasmannia lanceolata against Bacillus anthracis: Natural Resource Probing to Prevent Anthrax
}

\author{
Cameron Jay Lee ${ }^{1}$, Mitchell Henry Wright ${ }^{2, *}$, Anthony Carlson Greene ${ }^{1}$, Huda Aldosary', Ian Edwin Cock ${ }^{1,3, *}$ \\ 'School of Environment and Science, Griffith University, Brisbane, Queensland, AUSTRALIA. \\ 2Department of Research and Development, First Choice College, Gold Coast, Queensland, AUSTRALIA. \\ ${ }^{3}$ Environmental Futures Research Institute, Griffith University, Brisbane, Queensland, AUSTRALIA.
}

\begin{abstract}
Introduction: Bacillus anthracis is bacterial cause of the highly fatal, zoonotic disease anthrax. Tasmanian pepper (Tasmannia lanceolata) has been previously documented for its antiseptic properties against other pathogenic bacteria. This study sought to investigate the effectiveness of T. lanceolata as an inhibitory agent against B. anthracis. Methods: Tasmannia lanceolata berry and leaf extracts were prepared with either water or methanol as the extraction solvent. Growth inhibition was assessed against $B$. anthracis strain PMO through disc diffusion as assaying. The relative MIC values of each extract was quantified to evaluate efficacy as a sterilant. The degree of toxicity of each extract was achieved using the widely used Artemia franciscana nauplii bioassay. Results: T. lanceolata leaf extracts inhibited the growth of $B$. anthracis in the disc diffusion assay, with MIC values of 2333 and $1873 \mu \mathrm{g} / \mathrm{mL}$ respectively. In contrast, the $T$. lanceolata berry extracts were completely devoid of growth inhibitory activity. All $T$. lanceolata extracts (both berry and leaf) were non-toxic $\left(\mathrm{LC}_{50}\right.$ values substantially $>1000 \mu \mathrm{g} / \mathrm{mL}$ ) as determined via the Artemia franciscana bioassay. Conclusion: T. lanceolata berry and leaf extracts are not only non-toxicity, but also had moderate growth inhibitory bioactivity against $B$. anthracis, highlighting their potential in the treatment of anthrax.
\end{abstract}

Key words: Bacillus anthracis, Anthrax, Antioxidant, Zoonotic, Tasmannia lanceolata, Tasmanian pepper.

\section{Correspondence:}

Dr. Mitchell Henry Wright

Department of Research and Development, First Choice College,

Gold Coast, Queensland, AUSTRALIA.

Phone no: +91737357637

Email: mitchel|@fcc.edu.au

Dr. Ian Edwin Cock

'School of Environment and Science, Environmental Futures Research

Institute, Griffith University, Brisbane, Queensland, AUSTRALIA.

${ }^{3}$ Environmental Futures Research Institute, Griffith University, Brisbane,

Queensland, AUSTRALIA

Phone no: +61737357637

Email id: I.Cock@griffith.edu.au

DOI: $10.5530 /$ pc.2019.4.26

\section{INTRODUCTION}

Bacillus anthracis is a gram-positive, endospore-forming bacterium responsible for the disease anthrax. Whilst anthrax became notorious as a result of its use in bioterrorism in the early 2000s, livestock infection via endospore inhalation is a far more common manifestation of the disease. ${ }^{1}$ From a cultural standpoint, the most notable reporting of weaponised anthrax to date occurred in 2001, where B. anthracis spores were mailed to several locations in the US. This resulted in the infection of twenty people and this, among other incidents, resulted in widespread knowledge of weaponised anthrax. ${ }^{2}$ However, this practice is not new and in fact, anthrax has been weaponised and used in warfare, at least since medieval times. Looking past its associations with life-threatening infections and bioterrorism, $B$. anthracis is more importantly, one of many microorganisms naturally present in soil flora. In fact, inadvertent mass infections can be traced as far back as Ancient Egypt and it is theorised that the plagues described in ancient literature may have been mass infections of anthrax. ${ }^{3}$ Human anthrax is relatively uncommon compared to the prevalence in other vertebrates. Indeed, outbreaks in both wildlife and livestock are a significant health and economic issue in many parts of the world.

Anthrax infection in humans occurs when $B$. anthracis endospores enter the body through inhalation, ingestion or through abrasions in the skin. ${ }^{4}$ Members of the genus Bacillus can produce endospores in response to adverse environmental conditions. These endospore structures protect the bacterial genetic material until conditions are once again favourable to support growth. Endospores are metabolically dormant, non-dividing cells that are highly resistant to drying, heat and ultraviolet radiation and are the causative agent of disease initiation, rather than the vegetative cells. ${ }^{5}$ Once internalised, the body elicits an immune response, although the encapsulating endospore coating provides protection for the cells and can contribute to germination (a process known as macrophageenhanced germination). ${ }^{6}$ The germinating bacterium can then resume normal metabolic functions and toxins are subsequently produced. Inhalation anthrax is the most dangerous of the three forms of the disease and infection, often resulting in death unless rapid treatment is administered.

Tasmannia lanceolata (Poir.) A.C.Sm (commonly known as Tasmanian pepper or mountain pepperberry) is a shrub indigenous to the woodlands and cool temperate rainforests of Tasmania and south-eastern coastal regions of the mainland Australia, as far north as Sydney. ${ }^{8}$ It is a mediumlarge shrub of approximately 2-5 $\mathrm{m}$ in height. The leaves, berries and bark of this plant are traditionally used medicinally as well as a food source and flavouring agent. When dried, the berry forms a small, solid peppercorn suitable for crushing/milling and provides a spicy flavour and sharp aroma. Historically, the leaves have been used as herbs whilst its berries were used as a spice. Australian Aborigines used T. lanceolata as a therapeutic agent to treat stomach disorders. ${ }^{8,9}$ T. lanceolata has also been used traditionally for the treatment and cure of colic, venereal diseases, skin disorders and stomach aches. ${ }^{10}$ European colonists also documented the therapeutic properties of $T$. lanceolata and the bark was commonly used as a substitute for other herbal remedies and to treat scurvy (due to its high anti-antioxidant content). ${ }^{10}$ Despite its extensive ethnobotanical usage, limited scientific studies into the therapeutic properties of 
T. lanceolata have been published. It has been theorised that the plants high antioxidant capacity may provide therapeutic benefits. Indeed, investigations of $T$. lanceolata within our laboratory have highlighted the inhibition of bacterial growth by $T$. lanceolata berries, leaves and peppercorns against various pathogenic bacteria. ${ }^{11}$ as well as protozoal parasites. ${ }^{12}$ Despite the documented ability of T. lanceolata to inhibit the growth of many bacterial species, to the best of our knowledge there have been no studies focusing on T. lanceolata against B. anthracis growth. For this work, T. lanceolata berry and leaf extracts were prepared and their antibacterial potential was assessed against this pathogen to determine their potential in preventing and treating anthrax.

\section{MATERIALS AND METHODS}

\section{Plant collection and extraction}

T. lanceolata semi-dry berry (without seed) and dried leaf material was purchased from GoWild Harvest, Australia. Voucher specimens (TP-GU-GWH-2016B and TP-GU-GWH-2016L for the berry and leaf respectively) are stored in the School of Environment and Science, Griffith University. The berries were further dried in a Sunbeam food dehydrator until constant mass was acquired upon repeated measurements. All plant materials were stored at $-30^{\circ} \mathrm{C}$ until use. Extract preparation was performed as previously described..$^{13,14}$ The plant materials were thawed and freshly ground to a coarse powder prior to extraction. Individual $1 \mathrm{~g}$ quantities of the ground plant materials were weighing into each of two tubes and $50 \mathrm{~mL}$ of methanol or water were added respectively. Methanol (AR grade) was obtained from Ajax Fine Chemicals, Australia. The berry and leaf material were extracted in each solvent for $24 \mathrm{hr}$ at $4^{\circ} \mathrm{C}$ with gentle shaking. The extracts were subsequently filtered under vacuum through Whatman No. 54 filter paper, followed by drying in an Eppendorf concentrator 5301. The resultant dry extract was weighed and redissolved in $10 \mathrm{~mL}$ deionised water (containing $1 \%$ DMSO).

\section{Qualitative phytochemical studies}

Phytochemical analysis of the extracts for the presence of glycosides, flavonoids, phenolic compounds, alkaloids, anthraquinones, cardiac, polysteroids, saponins, tannins and triterpenoids were conducted using established assays..$^{15,16}$

\section{Antioxidant capacity}

The antioxidant capacity of each sample was assessed using the DPPH free radical scavenging method with modifications. ${ }^{17,18}$ Briefly, ascorbic acid $(0-25 \mu \mathrm{g}$ per well) was used as a reference and the absorbances recorded at $515 \mathrm{~nm}$. All were performed alongside controls on each plate and all tests performed in triplicate, each with three technical replicates $(n=9)$. The antioxidant capacity based on DPPH free radical scavenging ability was determined for each extract and expressed as $\mu$ g ascorbic acid equivalents per gram of original plant material extracted.

\section{Bacillus anthracis isolation and screening}

Bacillus anthracis was originally obtained from a water sample taken from Paralana hot springs $\left(30^{\circ} 17^{\prime} 49^{\prime \prime}\right.$ S, $\left.139^{\circ} 44^{\prime} 15^{\prime \prime} \mathrm{E}\right)$, South Australia. Isolation was achieved through successive culturing steps using a modified Peptone/Yeast Extract (PYE) agar as previously described. ${ }^{19,20}$ Genomic DNA was extracted using phenol/chloroform separation as previously described. ${ }^{21}$ PCR amplification of the $16 \mathrm{~S}$ rRNA gene was performed as previously described ${ }^{22}$ and sequence analyses of the isolate generated a contig of $1428 \mathrm{bp}$. The bacterium was revealed to be $99.92 \%$ similar to B. anthracis by EzTaxon and designated as Bacillus anthracis strain PMO. The GenBank accession number for the 16S rRNA gene sequence for the isolate is KR003287.

\section{Evaluation of antimicrobial activity}

Antimicrobial activity of all plant extracts was determined using a modified disc diffusion assay. ${ }^{23,24}$ Briefly, $100 \mu \mathrm{L}$ of the test bacteria were grown in $10 \mathrm{~mL}$ of fresh nutrient broth media until they reached a count of $\sim 10^{8}$ cells $/ \mathrm{mL}$. A $100 \mu \mathrm{L}$ volume of the bacterial suspension was spread onto nutrient agar plates and extracts were tested for antibacterial activity using $5 \mathrm{~mm}$ sterilised filter paper discs. Discs were infused with $10 \mu \mathrm{L}$ of individual test samples, allowed to dry and placed onto inoculated plates. The plates were allowed to stand at $4^{\circ} \mathrm{C}$ for $2 \mathrm{~h}$ before incubation at $30^{\circ} \mathrm{C}$ for $24 \mathrm{~h}$. The diameters of the zones of inhibition (ZOIs) were measured to the closest whole millimetre. Each assay was performed three times, each with technical triplicates $(n=9)$. Mean values $( \pm$ SD) are reported in this study. Standard discs of penicillin $(2 \mu \mathrm{g})$ and ampicillin $(10 \mu \mathrm{g})$ were obtained from Oxoid Ltd., Australia and used as positive controls for antibacterial activity. Filter discs impregnated with $10 \mu \mathrm{L}$ of distilled water were used as a negative control.

\section{Minimum inhibitory concentration (MIC) determination}

The Minimum Inhibitory Concentrations (MIC) of the extracts was determined as previously described. ${ }^{25,26}$ Briefly, the plant extracts were diluted in deionised water and tested across a range of concentrations. Discs were impregnated with $10 \mu \mathrm{L}$ of the extract dilutions, allowed to dry and placed onto inoculated plates. The assay was performed as outlined above and graphs of the zone of inhibition versus concentration were plotted. Ln linear regression was used to calculate the MIC values.

\section{Toxicity screening \\ Reference toxin for toxicity screening}

Potassium dichromate $\left(\mathrm{K}_{2} \mathrm{Cr}_{2} \mathrm{O}_{7}\right)$ (AR grade, Chem-Supply, Australia) was prepared as a $4 \mathrm{mg} / \mathrm{mL}$ solution in distilled water and serially diluted in artificial seawater for use in the Artemia franciscana nauplii bioassay.

\section{Artemia franciscana nauplii toxicity screening}

Toxicity was evaluated using a modified Artemia franciscana nauplii lethality assay. ${ }^{27}$ Briefly, $400 \mu \mathrm{L}$ of seawater containing approximately 43 (mean 43.2, $n=155$, SD 14.5) A. franciscana nauplii were added to wells of a 48 well plate and immediately used for bioassay. A volume of $400 \mu \mathrm{L}$ of diluted plant extracts or the reference toxin were transferred to the wells and incubated at $25 \pm 1^{\circ} \mathrm{C}$ under artificial light (1000 Lux). A negative control $(400 \mu \mathrm{L}$ seawater) was run in triplicate for each plate. All treatments were performed in at least triplicate. The wells were checked at regular intervals and the number of dead counted. The nauplii were considered dead if no movement of the appendages was observed within $10 \mathrm{sec}$. After $24 \mathrm{~h}$, all nauplii were sacrificed and counted to determine the total \% mortality per well. The $\mathrm{LC}_{50}$ with $95 \%$ confidence limits for each treatment was calculated using probit analysis.

\section{Statistical analysis}

Data is expressed as the mean \pm SD of three independent experiments, each with technical triplicates $(n=9)$.

\section{RESULTS}

Extraction of $1 \mathrm{~g}$ of the $T$. lanceolata plant materials with the solvents yielded dried plant extracts ranging from $111 \mathrm{mg}$ ( $T$. lanceolata aqueous berry) to $144 \mathrm{mg}$ (methanolic T. lanceolata leaf extract; Table 1). The dried extracts were resuspended in $10 \mathrm{~mL}$ of deionised water (containing $1 \%$ DMSO) resulting in the extract concentrations shown in Table 1.

Qualitative phytochemical studies showed little difference between the aqueous and methanolic extracts. Similarly, few differences were noted between the phytochemical classes detected between the berry and 


\begin{tabular}{|c|c|c|c|c|c|c|c|c|c|c|c|c|c|c|c|}
\hline 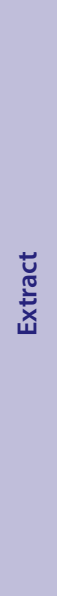 & 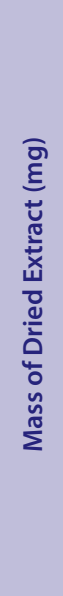 & 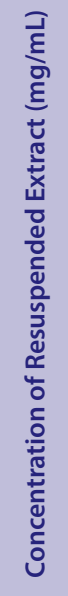 & 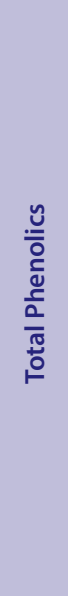 & 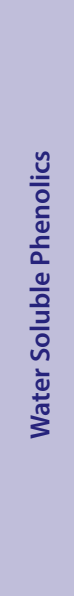 & 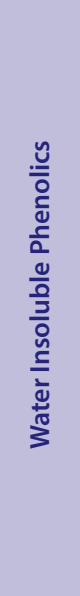 & 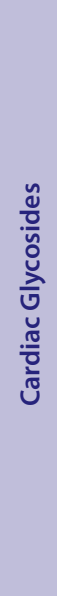 & 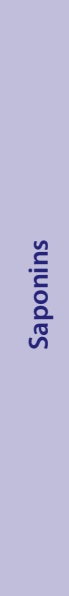 & 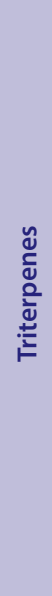 & 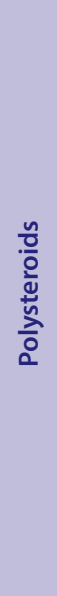 & 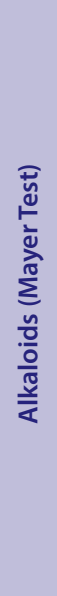 & 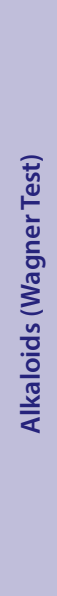 & \begin{tabular}{l}
$\frac{n}{0}$ \\
\hdashline 0 \\
$\frac{0}{0}$ \\
$\frac{0}{0}$ \\
$\frac{\pi}{4}$
\end{tabular} & 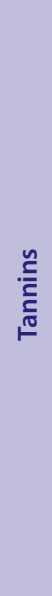 & 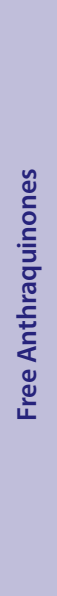 & 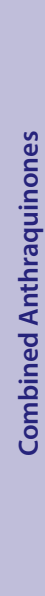 \\
\hline ML & 144 & 14.4 & +++ & +++ & +++ & - & +++ & + & - & - & - & +++ & - & - & - \\
\hline $\mathrm{AL}$ & 134 & 13.4 & +++ & +++ & +++ & - & ++ & - & - & - & - & +++ & - & - & - \\
\hline MF & 171 & 17.1 & +++ & +++ & +++ & - & ++ & + & - & - & - & +++ & - & - & - \\
\hline $\mathrm{AF}$ & 111 & 11.1 & +++ & +++ & +++ & - & - & - & - & - & - & +++ & - & - & - \\
\hline
\end{tabular}

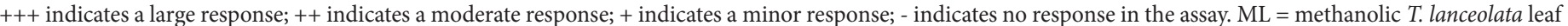
extract; $\mathrm{AL}=$ aqueous $T$. lanceolata leaf extract; $\mathrm{MF}=$ methanolic $T$. lanceolata berry extract; $\mathrm{AF}=$ aqueous $T$. lanceolata berry extract.

corresponding fruit extracts. High levels of polyphenolic compounds (both water soluble and insoluble) were extracted in all the T. lanceolata extracts. Similarly, high levels of flavonoids and moderate levels of saponins were detected in the aqueous and methanolic berry and leaf extracts.

To assess the inhibitory activity of the crude T. lanceolata plant extracts against $B$. anthracis, $10 \mu \mathrm{L}$ aliquots of each were screened using standard disc diffusion assays. Antibacterial activity against B. anthracis was observed in all 4 extracts tested (Figure 1). The methanolic and aqueous leaf extract inhibited B. anthracis growth, with ZOIs of $6.7 \pm 0.58 \mathrm{~mm}$ and $7.0 \pm 0.0 \mathrm{~mm}$ respectively. In contrast, the berry extracts were completely devoid of growth inhibitory activity. The ampicillin control had inhibi-

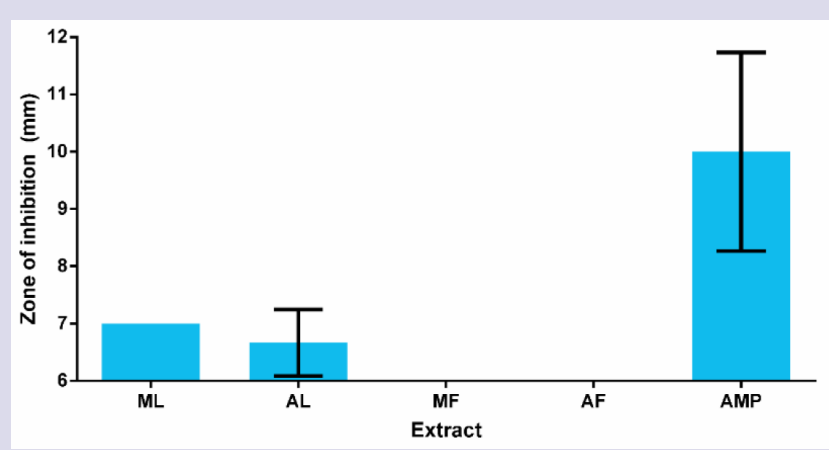

Figure 1: Growth inhibitory activity of $T$. lanceolata leaf and berry extracts against the $B$. anthracis environmental isolate $\mathrm{ML}=$ methanolic $T$. lanceolata leaf extract; $\mathrm{AL}=$ aqueous $T$. lanceolata leaf extract; $\mathrm{MF}=$ methanolic $T$. lanceolata berry extract; $\mathrm{AF}=$ aqueous $\mathrm{T}$. lanceolata berry extract. AMP = Ampicillin $(10 \mu \mathrm{g})$. Measured as zones of inhibition $(\mathrm{mm})$ and expressed as mean zones of inhibition \pm SD. tory zones of $10.0 \pm 1.7 \mathrm{~mm}$, indicating that the assay was functioning correctly.

The antimicrobial efficacy was further quantified by determining the MIC values (Table 2). Only the leaf extracts were growth inhibitory. Therefore, no MIC values are reported for the berry extracts. Both the methanolic and aqueous leaf extracts had similar MIC values $(\sim 1900$ $2300 \mu \mathrm{g} / \mathrm{mL}$ ) and are indicative of moderate growth inhibitory activity.

All extracts were initially screened undiluted in the Artemia nauplii assay as a measure of toxicity (Figure 2). For comparison, the reference toxin potassium dichromate $(1000 \mu \mathrm{g} / \mathrm{mL})$ was also tested in the bioassay. The potassium dichromate reference toxin was rapid in its onset, promoting nauplii death within the first $3 \mathrm{~h}$ of exposure with $100 \%$ mortality evident following $4-5 \mathrm{hr}$ (unpublished results). Similarly, all the T. lanceolata extracts displayed significant mortality rates following $24 \mathrm{~h}$ exposure $(>50 \%)$. The extracts were therefore tested across a range of dilutions to determine the $\mathrm{LC}_{50}$ values. Notably, all extracts had $\mathrm{LC}_{50}$ values substantially $>1000 \mu \mathrm{g} / \mathrm{mL}$. As $\mathrm{LC}_{50}$ values $>1000 \mu \mathrm{g} / \mathrm{mL}$ have

Table 2: Minimum inhibitory concentration $(\mu \mathrm{g} / \mathrm{mL})$ of the plant extracts and $\mathrm{LC}_{50}$ values $(\mu \mathrm{g} / \mathrm{mL})$ in the Artemia nauplii bioassay.

\begin{tabular}{ccc}
\hline Extract / Control & MIC & LC $_{50}$ \\
\hline ML & 2333 & 2096 \\
AL & 1873 & 2665 \\
MF & - & 2573 \\
AF & - & 2376 \\
PC & - & 186 \\
SW & & \\
\hline
\end{tabular}

Numbers indicate the mean MIC and $\mathrm{LC}_{50}$ values of triplicate determinations. indicates no inhibition. $\mathrm{ML}=$ methanolic $T$. lanceolata leaf extract; $\mathrm{AL}=$ aqueous T. lanceolata leaf extract; $\mathrm{MF}=$ methanolic $T$. lanceolat $a$ berry extract; $\mathrm{AF}=$ aqueous T. lanceolata berry extract; $\mathrm{PC}=$ Potassium dichromate; $\mathrm{SW}=$ artificial seawater. 


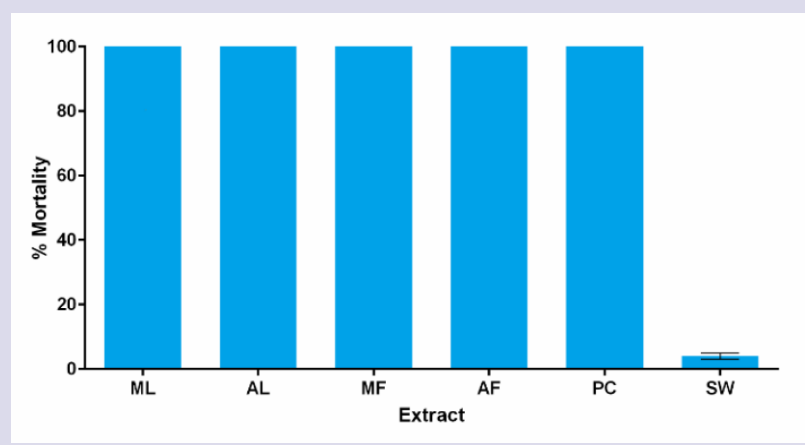

Figure 2: The lethality of the T. lanceolata extracts $(2000 \mu \mathrm{g} / \mathrm{mL})$ alongside the potassium dichromate control $(1000 \mu \mathrm{g} / \mathrm{mL})$ towards Artemia franciscana nauplii after $24 \mathrm{hr}$ exposure. $\mathrm{ML}=$ methanolic $T$. lanceolata leaf extract; $\mathrm{AL}=$ aqueous $\mathrm{T}$. lanceolata leaf extract; $\mathrm{MF}=$ methanolic $T$. lanceolata berry extract; $\mathrm{AF}=$ aqueous $T$. lanceolata berry extract; $\mathrm{PC}=$ potassium dichromate; $\mathrm{SW}=$ artificial seawater (negative control). Results are expressed as mean \% mortality \pm SD.

previously been defined as nontoxic, ${ }^{27}$ all T. lanceolata extracts were determined to be non-toxic.

\section{DISCUSSION}

This study was performed to investigate the antibacterial potential T. lanceolata to inhibit the growth of $B$. anthracis, thereby blocking the induction of anthrax treating the disease once it is established. Despite the efficacy of commonly used antibiotics, recent increases in bacterial resistances have made the development of new antibiotic therapies a high priority ${ }^{28}$ Furthermore, parallel decreases in the introduction novel antibiotic therapies in recent years has further compounded this problem. Because of this, interests in the potential for medicinal plants for new antibiotic chemotherapies has drastically increased in recent years. ${ }^{29}$ Numerous investigations into high antioxidant plants have reported on their antibacterial properties against a broad panel of bacterial pathogens, including those capable of inhibiting $B$. anthracis growth. ${ }^{24,25}$ With respect to $T$. lanceolata, in addition to inhibiting bacterial pathogens, ${ }^{12-16}$ extracts prepared from the berries and leaves have recently been reported to inhibit the proliferation of the gastrointestinal protozoan parasite Giardia duodenalis. ${ }^{30}$ Demonstrating its therapeutic potential against both prokaryotic and eukaryotic pathogens. However, despite the relative wealth of information into the therapeutic potential of T. lanceolata, it is yet to be comprehensively studied for antibacterial activity against an endospore forming bacterial pathogen. Herein, we report moderate growth inhibitory activity for T. lanceolata berry and leaf extracts against the bacterial cause of the disease anthrax, a potentially fatal infection acquired through inhalation, ingestion or through skin abrasions in contact with $B$. anthracis.

B. anthracis growth inhibitory activity was evident in the T. lanceolata fruit and leaf extracts. Therefore, these extracts have potential for the prevention and treatment of anthrax and are potential targets for drug discovery. Detailed analyses into the phytochemistry of the T. lanceolata fruit and leaf extracts was beyond the scope of this study. However, several notable compounds have been previously reported in T. lanceolata extracts and essential oils. ${ }^{8}$ These include multiple monoterpenoids (e.g. 1, 8-cineole, terpinen-4-ol, $\alpha$-pinene and $\beta$-pinene) and sesquiterpenoids (particularly polygodial), flavonoids (including quercetin and rutin), other phenolics (including coumaric acid and caffeic acid) and hydrocarbons. Many of these compounds have also been isolated from other plant species and have been shown to have potent antimicrobial activity $^{8}$ Therefore, these components may also contribute to the $B$. anthracis growth inhibitory properties of the extracts tested in this study. Of particular note, high abundances of the sesquiterpenoid polygodial have been reported in T. lanceolata berry and leaf extracts, although higher relative levels have been reported in the berry extracts. Indeed, polygodial can account for approximately $40 \%$ of commercial T. lanceolata essential oil components. ${ }^{8,31}$ Interestingly, several studies have reported the therapeutic properties of this compound, including its antibacterial, ${ }^{31}$ antifungal, ${ }^{32}$ anti-hyperalgesia, ${ }^{33}$ anti-inflammatory, antiallergic and vasorelaxation activities. ${ }^{34}$ Other structurally similar sesquiterpenoids have also been reported in $T$. lanceolata extracts prepared in a similar way to our study. ${ }^{30}$ Of further interest, salidroside has previously been reported in T. lanceolata berry and leaf methanolic and aqueous extracts. Salidroside has been linked with antibacterial and anti-parasitic activity in multiple plants. Plants of the genus Warburgia are known to have significant levels of s salidroside ${ }^{35}$ and several Warburgia spp. have been reported to have strong antimicrobial and antiparasitic activities. ${ }^{36,37}$

T. lanceolata berry and leaf extracts have also been reported to contain an abundance of gallotannin components. ${ }^{30}$ Gallotannins have been reported to inhibit the growth of a broad spectrum of microbial species $^{38}$ via binding cell surface lipoteichoic acid and proline-rich cell surface proteins. ${ }^{39,40}$ and by inhibiting glucosyltransferase enzymes. ${ }^{41}$ The stilbene combretastatin A1 has also been putatively identified in all T. lanceolata berry extracts, ${ }^{30}$ albeit, in low abundance. Combretastatin's are well known for their potent ability to block cancer cell progression and induce apoptosis by binding intracellular tubulin, thereby disrupting microtubule formation. ${ }^{42}$ Combretastatin's act in a similar fashion to that of colchicine (N-[(7S)-1,2,3,10-tetramethoxy-9-oxo-5,6,7,9tetrahydrobenzo[a]heptlen-7-yl] acetamide) by binding the colchicine's binding site in tubulin. ${ }^{43}$ Thus, the T. lanceolata combretastatin's may block bacterial replication events.

The findings reported here also indicate that the T. lanceolata berry and leaf extracts were nontoxic, with $\mathrm{LC}_{50}$ values substantially $>2000 \mu \mathrm{g} / \mathrm{mL}$. Toxicity was assessed in this study using the test organism A. franciscana. The lack of toxicity of the T. lanceolata extracts in our study indicates that the extracts are safe for medicinal usage. This is hardly surprising as T. lanceolata is highly nutritious and has long been used as a spice (berries) and herb (leaves). However, whilst the extracts examined in this report have potential as $B$. anthracis growth inhibitory agents, caution is required before these compounds can be applied to medicinal purposes. Toxicity towards $A$. franciscana has previously been shown to correlate well with toxicity towards human cells for many toxins. ${ }^{30}$ However, further studies are required to determine whether this is also true for the T. lanceolata extracts examined in these studies. The results of this study indicate that the T. lanceolata extracts examined warrant further study due to their B. anthracis growth inhibitory activity. Purification and identification of the bioactive components is needed to examine the mechanisms of action of these agents.

\section{CONCLUSION}

The lack of toxicity and the moderate B. anthraicis growth inhibitory activity of the T. lanceolata leaf extracts demonstrate their potential as therapeutic agents for the prevention and treatment of anthrax.

\section{ACKNOWLEDGEMENT}

Financial support for this work was provided by the Environmental Futures Research Institute and the School of Environment and Science, Griffith University, Australia. 


\section{CONFLICT OF INTEREST}

The authors declare no confluicts of interest

\section{ABBREVIATIONS}

DMSO: Dimethyl sulfoxide; LC50: The concentration required to achieve $50 \%$ mortality; MIC: Minimum inhibitory concentration. REFERENCES

1. Elad D. An unholy disease in the Holy Land: The history of anthrax between the Jordan River and the Mediterranean Sea (1909-2012). The Veterinary Journal. 2014;199(3):319-23.

2. Sternbach G. The History of Anthrax. The Journal of Emergency Medicine. 2003;24(4):463-7.

3. Ehrenkranz NJ, Sampson DA. Origin of the Old Testament Plagues: Explications and Implications. Yale Journal of Biology and Medicine. 2008;81(1):31-42.

4. Hampson $K$, Lembo T, Bessell $P$, et al. Predictability of anthrax infection in the Serengeti, Tanzania. Journal of Applied Ecology. 2011;48(6):1333-44.

5. Watson A, Keir D. Information on which to base assessments of risk from environments contaminated with anthrax spores. Epidemiology and Infection. 1994;113(3):479-90.

6. Ireland JAW, Hanna PC. Macrophage-Enhanced Germination of Bacillus anthracis Endospores Requires gerS. Infection and Immunity. 2002;70(10):5870-2.

7. Dixon TC, Meselson M, Guillemin J, et al. Anthrax. The New England Journal of Medicine. 1999;341:815-26.

8. Cock IE. The phytochemistry and chemotherapeutic potential of Tasmannia lanceolata (Tasmanian pepper): A review. Pharmacog Commn. 2013;3(4):13-25.

9. Cock IE. Medicinal and aromatic plants - Australia. In Ethnopharmacology section, Biological, Physiological and Health Sciences; Encyclopedia of Life Support Systems (EOLSS), Developed under the auspices of UNESCO, EOLSS Publishers, Oxford, UK. 2011. (http://www.eolss.net).

10. Netzel M, Netzel G, Tian Q, Schwartz S, Konczak I. Native Australian fruits - A novel source of antioxidants for food. Innov Food Sci Emerg Technol. 2007;8(3):339-46. DOI: 10.1016/j.ifset.2007.03.007.

11. Wright MH, Lee CJ, Arnold MSJ, Shalom J, White A, Greene AC, et al. GC-MS analysis of Tasmannia lanceolata extracts which inhibit the growth of the pathogenic bacterium Clostridium perfringens. Pharmacog J. 2017;9(5):626-37. DOI: 10.5530/pj.2017.5.100

12. Cock IE, Sirdaarta J, WinnettV, Matthews B. Phytochemical analysis of Tasmannia lanceolata extracts that inhibit the microbial triggers of rheumatoid arthritis. South African Journal of Botany. 2015;(98):174. DOI: 10.1016/j.sajb.2015.03.029

13. Wright MH, Arnold MSJ, Lee CJ, Courtney R, Greene AC, Cock IE. Qualitative phytochemical analysis and antibacterial activity evaluation of Indian Terminalia spp. against the pharyngitis causing pathogen Streptococcus pyogenes. Pharmacognosy Communications. 2016;6(2):85-92. DOI: 10.5530/pc.2016.2.6

14. Wright MH, Sirdaarta J, Matthews B, Greene AC, et al. Growth inhibitory activity of Kakadu plum extracts against the opportunistic pathogen Clostridium perfringens: New leads in the prevention and treatment of clostridial myonecrosis. Pharmacog Commn. 2016;8(2):144-53. DOI: 10.5530/pc.2016.2.7

15. Lee CJ, Wright MH, Arnold MSJ, Greene AC, Cock IE. Inhibition of Streptococcus pyogenes growth by native Australian plants: New approaches towards the management of impetigo, pharyngitis and rheumatic heart disease. Pharmacognosy Communications. 2016;6(3):164-73.

16. Wright $\mathrm{MH}$, Matthews $B$, White A, Cock IE. Bioactive compounds sourced from Terminalia spp. in bacterial malodour prevention: An effective alternative to chemical additives. Int J Cosmetic Sci. 2019. DOI: 10.1111/ics.12567

17. McManus K, Wood A, Wright MH, Matthews B, et al. Terminalia ferdinandiana Exell. Extracts inhibit the growth of body odour-forming bacteria. Int J Cosmetic Sci. 2017;39(5):500-10. DOI: 10.1111/ics.12403

18. Jamieson N, Sirdaarta J, Cock IE. The anti-proliferative properties of Australian plants with high antioxidant capacities against cancer cell lines. Pharmacognosy Communications. 2014;4(4):71-82. DOI: 10.5530/pc.2014.4.8

19. Wright MH, Geszvain K, Oldham VE, Luther GW III, Tebo BM. Oxidative formation and removal of complexed Mn (III) by Pseudomonas species. Front Microbiol. 2018;9(560):1-11. DOI: 10.3389/fmicb.2018.00560

20. Wright MH, Farooqui SM, White AR, Greene AC. Production of manganese oxide nanoparticles by Shewanella species. Appl Environ Microbiol
2017;82(17):5402-9. DOI: 10.1128/AEM.00663-16.

21. Wright $\mathrm{MH}$, Adelskov J, Greene AC. Bacterial DNA extraction using individual enzymes and phenol/chloroform separation. J Microbiol Biol Educ. 2017; 18(2):18.2.48. sDOI: 10.1128/jmbe.v18i2.1348.

22. Wright MH, Hanna JG, Pica DA, Tebo BM. Pseudomonas laurentiana sp. nov an $\mathrm{Mn}$ (III)-oxidizing Bacterium Isolated from the St. Lawrence Estuary. Pharmacog Commn. 2018:8(4);153-7. DOI: 10.5530/pc.2018.4.32.

23. Wright MH, Matthews B, Arnold MSJ, Greene AC, et al. The prevention of fish spoilage by high antioxidant Australian culinary plants: Shewanella putrefaciens growth inhibition. Int J Food Sci Technol. 2016;51(3):801-13. DOI: 10.1111/ ijfs. 13026 .

24. Wright $\mathrm{MH}$, Greene $\mathrm{AC}$, Cock IE. Inhibition of Bacillus anthracis growth by Australian native plants used traditionally as antibacterial medicines. Pharmacog Commn. 2015;7(6):389-96. DOI: 10.5530/pj.2015.6.13.

25. Wright MH, Sirdaarta J, White A, Greene AC, et al. GC-MS headspace analysis of Terminalia ferdinandiana fruit and leaf extracts which inhibit Bacillus anthracis growth. Pharmacog J. 2017;9(1):73-82. DOI: 10.5530/pj.2017.1.14.

26. Shalom J, Cock IE. Terminalia ferdinandiana Exell. fruit and leaf extracts inhibit proliferation and induce apoptosis in selected human cancer cell lines. Nutrition and Cancer. 2018;70(4):579-93. DOI: 10.1080/01635581.2018.1460680.

27. Ruebhart DR, Wickramasinghe W, Cock IE. Protective efficacy of the antioxidants Vitamin $\mathrm{E}$ and Trolox ${ }^{\mathrm{TM}}$ against Microcystis aeruginosa, microcystin-LR and menadione toxicity in Artemia franciscana nauplii. Journal of Toxicology and Environmental Health, Part A. 2009;72(24):1567-75.

28. Cheesman MJ, Ilanko A, Blonk B, Cock IE. Developing new antimicrobial therapies: Are synergistic combinations of plant extracts/compounds with conventional antibiotics the solution?. Pharmacog Rev. 2017;11(22):57-72. DOI: 10.4103/phrev.phrev_21_17.

29. Aiyegoro OA, Okoh Al. Use of bioactive plant products in combination with standard antibiotics: Implications in antimicrobial chemotherapy. J Med Plants Res. 2009:3(13):1147-52.

30. Rayan P, Matthews B, McDonnell P, Cock IE. Phytochemical analysis of Tasmannia lanceolata extracts and inhibition of Giardia duodenalis proliferation. Pharmacognosy Journal. 2016;8(3):291-9. DOI: 10.5530/pj.2016.3.19

31. Kubo I, Fujita K, Lee SH, et al. Antibacterial activity of polygodial. Phytother Res. 2005;19(12):1013-7. DOI: 10.1002/ptr.1777

32. Alves TM, Ribeiro FL, Kloos H, et al. Polygodial, the fungitoxic component from the Brazilian medicinal plant Polygonum punctatum. Mem Inst Oswaldo Cruz. 2001;96(6):831-3. DOI: 10.1590/s0074-02762001000600016

33. Mendes GL, Santos ARS, Campos MM, et al. Anti-hyperalgesic properties of the extract and of the main sesquiterpene polygodial isolated from the barks of Drymis winteri (Winteraceae). Life Sci. 1998;63(5):369-81. DOI: 10.1016/s00243205(98)00285-9

34. DaCunha FM, Frode TS, Mendes GL, et al. Additional evidence for the antiinflammatory and anti-allergic properties of the sesquiterpene polygodial. Life Sci. 2001;70(2):159-69. DOI: 10.1016/s0024-3205(01)01387-x

35. Maroyi A. The genus Warburgia: A review of its traditional uses and pharmacology. Pharmaceut Biol. 2014:52(3):378-91. DOI: 10.3109/13880209.2013.837935

36. Ngure PK, Tonui WK, Ingonga J, et al. In vitro antileishmanial activity of extracts of Warburgia ugandensis (Canellaceae), a Kenyan medicinal plant. J Med Plant Res. 2009;3(2):61-6.

37. Ahmed M, Laing MD, Nsahlai IV. In vitro anthelmintic activity of crude extracts of selected medicinal plants against Haemonchus contortus from sheep. J Helminthol. 2013;87(2):174-9. DOI: 10.1017/S0022149X1200020X

38. Buzzini $P$, Arapitsas $P$, Goretti $M$, et al. Antimicrobial activity of hydrolysable tannins. Mini-Rev Med Chem. 2008;8(12):1179-87.

39. Wolinsky LE, Sote EO. Isolation of natural plaque-inhibiting substances from 'Nigerian chewing sticks'. Caries Res. 1984;18(3):216-25. DOI: 10.1159/000260768

40. Hogg SD, Embery G. Blood-group-reactive glycoprotein from human saliva interacts with lipoteichoic acid on the surface of Streptococcus sanguis cells. Arch Oral Biol. 1982;27(3);261-8. DOI: 10.1016/0003-9969(82)90060-7

41. Wu-Yuan CD, Chen CY, Wu RT. Gallotannins inhibit growth, water-soluble glucan synthesis and aggregation of ssStreptococci mutans. J Dental Res. 1988:67(1);51-5. DOI: 10.1177/00220345880670011001

42. Dark GG, Hill SA, Prise VE, et al. Combretastatin A-4, an agent that displays potent and selective toxicity towards tumor vasculature. Cancer Res. 1997;57(10):1829-34

43. Bhardwaj S, Bakshi S, Chopra B, et al. Synthesis of combretastatin analogues with their potent anticancer activity. Int J Res Pharm Sci. 2010;1(4):414-6. 


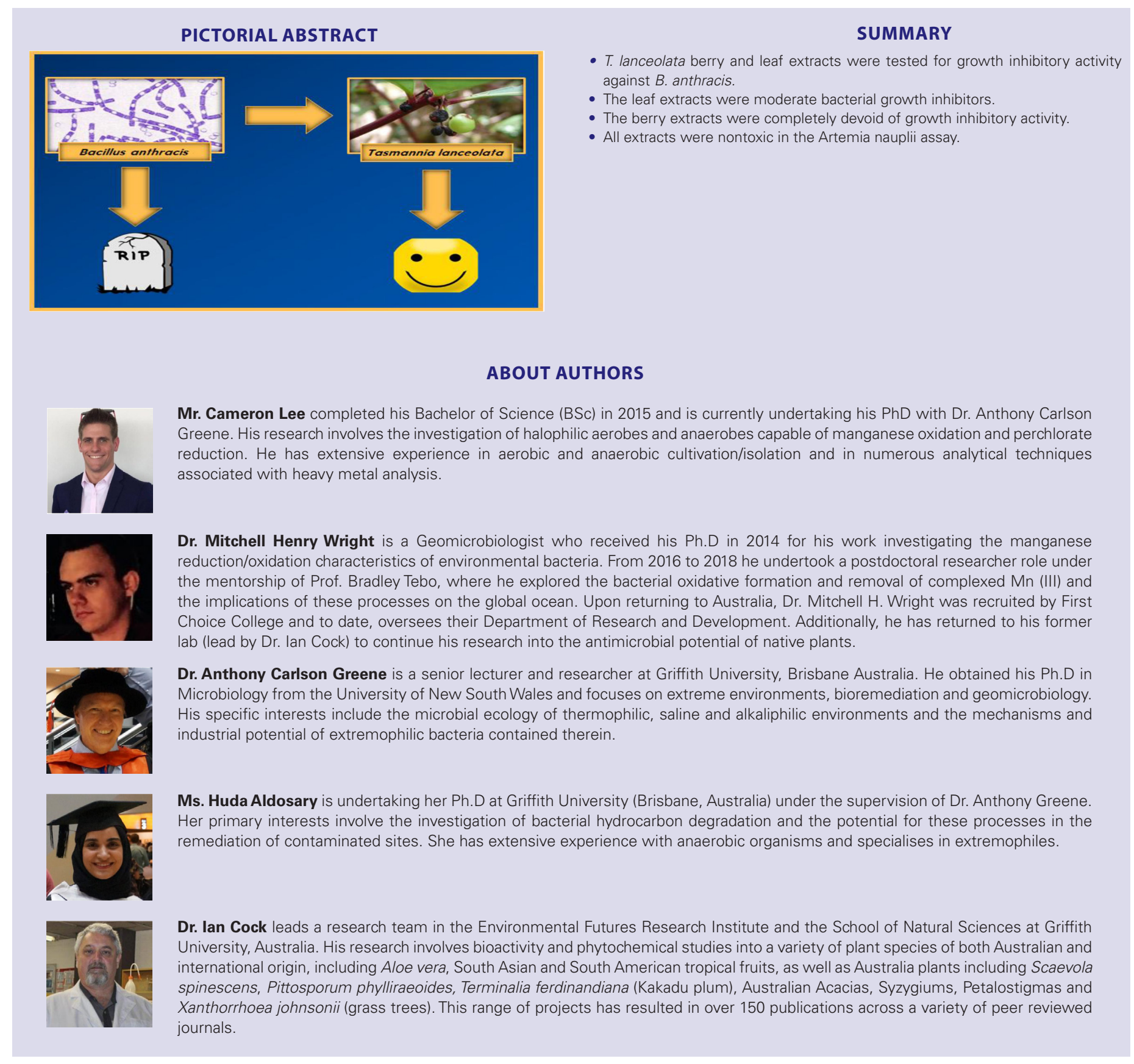

